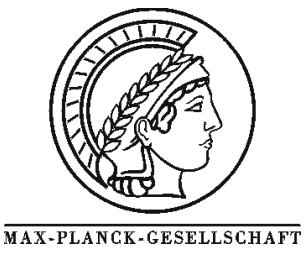

\title{
The Role of Sub-Surface Oxygen in the Silver-Catalyzed, Oxidative Coupling of Methane
}

\author{
A.J. Nagy, G. Mestl ${ }^{*}$, R. Schlögl \\ Department of Inorganic Chemistry, Fritz-Haber-Institute of the MPG, Faradayweg 4-6, 14195 Berlin, Germany \\ * Corresponding author: e-mail mestl@ffhi-berlin.mpg.de, phone +49 308413 4440, fax +49 3084134401 \\ Received 03 February 1999; accepted 09 August 1999
}

\begin{abstract}
The silver-catalyzed, oxidative coupling of methane to $\mathrm{C}_{2}$ hydrocarbons (OCM) is shown to be an extremely structure-sensitive reaction. Reaction-induced changes in the silver morphology lead to changes in the nature and extent of formation of various bulk and surface-terminating crystal structures. This, in-turn, impacts the adsorption properties and diffusivity of oxygen in silver which is necessary to the formation of subsurface oxygen. A strongly-bound, Lewis-basic, oxygen species which is intercalated in the silver crystal structure is formed as a result of these diffusion processes. This species is referred to as $\mathrm{O}_{\gamma}$ and acts as a catalytically active site for the direct dehydrog enation of a variety of organic reactants. It is found that the activation energy for methane coupling over silver of $138 \mathrm{~kJ} / \mathrm{mol}$ is nearly identical to the value of $140 \mathrm{~kJ} / \mathrm{mol}$ for oxygen diffusion in silver measured under similar conditions. This correlation between the diffusion kinetics of bulk-dissolved oxygen and the reaction kinetics of the oxidative coupling of methane to $\mathrm{C}_{2}$ hydrocarbons suggests that the reaction is limited by the formation of $\mathrm{O}_{\gamma}$ via surface segregation of bulk dissolved oxygen. Catalysis over fresh silver catalysts indicates an initially preferential oxidation of $\mathrm{CH}_{4}$ to complete oxidation products. This is a result of the reaction of methane with surface bound atomic oxygen which forms preferentially on high-index terminating crystalline planes. Reaction-induced facetting of the silver results in a restructuring of the catalyst from one which initially catalyzes the complete oxidation of methane to $\mathrm{CO}_{\mathrm{x}}$ and water to a catalyst which preferentially catalyzes the formation of coupling products. This represents an extremely dynamic situation in which a solid-state restructuring of the catalyst results in the formation of a Lewis-basic, silver-oxygen species which preferentially catalyzes the dehydrogenation of organic molecules.
\end{abstract}

Keywords: OCM, Oxidative Coupling of Methane, Silver, Electrolytic, Diffusion, Recrystallization, Facetting, Morphology, Kinetics, Sintering

\section{Introduction}

Silver is used industrially as a catalyst for the partial oxidation of methanol to formaldehyde $e^{1,2,3}$ and for the epoxidation of ethylene to ethylene epoxide ${ }^{4,5,6}$. It is generally accepted that the particularly high activity and selectivity of silver for these reactions is due to its ability to activate molecular oxygen in a variety of ways leading to the creation of different types of silver-bound oxygen species. A wealth of literature exists on the silver-oxygen interaction ${ }^{7,8,9,10,11,12}$. Much of this literature is, unfortunately, contradicting and a great deal of ambiguity still exists as to the exact nature of the various oxygen species formed.

Silver is known to undergo morphological restructuring as a result of high temperature treatment in various gas atmos- pheres ${ }^{9,13,14,15,16}$. This study was carried out in an attempt to test the hypothesis that a number of different oxygen species are formed on silver which behave differently when reacting with different organic reactants (methane, methanol). A variety of different nomenclatures for these species have been used in the literature. The nomenclature presented in this paper is internally consistent and is also consistent with previous publications made by our group. These species have been previously characterized with a variety of spectroscopic techniques ${ }^{17,18,19,20,21}$. They differentiate themselves in both their electronic properties as well as their location on and in the silver catalyst. The first species is referred to as $\mathrm{O}_{\alpha}$. This is chemisorbed atomic oxygen which is believed to catalyze the oxi-dehydrogenation of methanol 
to formaldehyde as well as the complete oxidation to $\mathrm{CO}_{2}$ and water ${ }^{22}$. It is a highly-reactive oxygen species exhibiting a strongly nucleophilic character. It has a thermal-desorption temperature of approximately $573 \mathrm{~K}$ and shows an XPS binding energy of $530 \mathrm{eV} . \mathrm{O}_{\alpha}$ may exist at temperatures in excess of this desorption temperature if a partial pressure of oxygen exists in the gas phase. The second species is referred to as $\mathrm{O}_{\beta}$ and is assigned to bulk-dissolved oxygen. It shows a broad-asymmetric thermal desorption peak at approximately $773 \mathrm{~K}$, whose desorption maximum shows a strong dependence on oxygen dosing pressure and temperature. It is also characterized by an XPS signal showing a broad peak centered at $530.3 \mathrm{eV}$. The third species is referred to as $\mathrm{O}_{\gamma}$. $\mathrm{O}_{\gamma}$ is characterized by an unsaturated, thermal-desorption signal beginning at approximately $973 \mathrm{~K}$ and an XPS binding energy of $529 \mathrm{eV}$. It is assigned to stronglybound, intercalated oxygen which diffuses via interstitialcy diffusion into the uppermost layers of the reconstructed silver surface where it may react with gaseous reactants. Previous work has shown that oxygen diffusion in silver is highly anisotropic. ${ }^{23}$ Interstitial diffusion was shown to occur primarily in the [110] direction through channels formed in the (110) plane of the silver crystallites. Diffusion through the (111) planes is activated only at elevated temperatures $(\mathrm{T}>923 \mathrm{~K})$. This high-temperature diffusion occurs via the interstitialcy diffusion of oxygen (lattice substitution) through the closely packed (111) facet terraces.

The oxidative coupling of methane to $\mathrm{C}_{2}$ hydrocarbons was chosen as a test reaction. A major reason in deciding to study the OCM reaction stems from the fact that a detailed study of the dependence of reaction kinetics of the more industrially-relevant formaldehyde synthesis reaction is hampered by exceptionally high reactant conversions which result in diffusion-controlled reaction kinetics. The reaction of methanol and oxygen over silver almost always results in complete oxygen consumption ${ }^{25-28}$. The relatively slow reaction rates typical for the OCM reaction allow for a much more thorough investigation than is possible when studying the partial oxidation of methanol to formaldehyde. In addition, both the OCM reaction and the formaldehyde synthesis reaction take place in similar temperature regimes $(\mathrm{T}>873$ $\mathrm{K})$ and are believed to be catalyzed by $\mathrm{O}_{\gamma}{ }^{24,28}$. Both reactions require the dehydrogenation of a $\mathrm{C}-\mathrm{H}$ bond as a key step in the formation of the desired product and have a single carbon atom forming the organic substrate. The OCM reaction provides information about the ability of the system to directly dehydrogenate an R-H bond as opposed to completely oxidizing the organic substrate (Fig. 1). Finally, in both cases, no oxygen insertion in the reactant molecule is desired. The desired reactions are pure dehydrogenation reactions. The OCM reaction is, therefore, an ideally suited test reaction for studying the high-temperature behavior of silver-catalyzed, partial-oxidation reactions in general. It is not assumed here that one may simply derive information using one reaction and apply this with liberty to any other reaction. One may, however, with careful consideration of the relevant reaction parameters, obtain a great deal of information from the OCM reaction which may be applied to the technically, more relevant, formaldehyde synthesis reaction. A detailed comparison of both reactions is made where appropriate in order to show where possible weak points exist in the interpretation of one or the other.

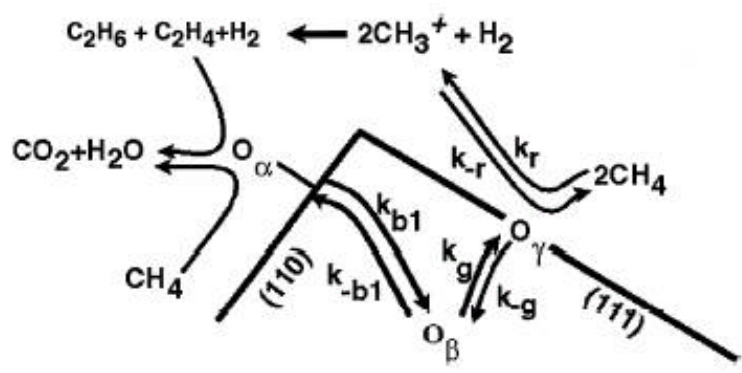

Fig. 1 Reaction scheme showing the various oxygen species formed in silver and their participation in high-temperature oxi-dehydrogenation reactions.

\section{Experimental}

The reactions were carried out in a small, quartz-tube reactor (10 mm O.D., $8 \mathrm{~mm}$ I.D.) with a $2 \mathrm{~cm}$ isothermal zone and a total length of $20 \mathrm{~cm}$. A K-Type thermocouple was attached to the tube wall directly adjacent to the catalyst bed. The high activity of the thermocouple made its location directly in the catalyst bed impossible. Quartz rods were inserted above and below the catalyst bed and were held in place by quartz-wool plugs in order to minimize contributions from gas-phase reactions. Electrolytic silver was generously provided by the BASF AG. Qualitative EDX analysis showed the presence of small amounts of $\mathrm{Na}, \mathrm{Cl}, \mathrm{Si}$ and $\mathrm{C}$ contaminants. The catalyst particles were $0.2-0.4 \mathrm{~mm}$ in diameter. $\mathrm{SiO}_{2}$ was mixed with the silver sample in order to reduce sintering effects and the formation of hot spots. These mixtures contained equivalent weights of $\mathrm{Ag}$ and $\mathrm{SiO}_{2} . \mathrm{SiO}_{2}$ was purchased from Aldrich $(99.999 \%)$ and consists primarily of the cristobalite phase. Blank runs showed this material to be catalytically inactive. Helium (5.0) was purified with an Oxisorb filter and was used as a carrier gas for all runs. Oxygen (5.0) and methane (3.5) were purchased from Linde and were used without further purification. The space velocity was $10,480 \mathrm{hr}^{-1}$ for the Ag sample mixed with $\mathrm{SiO}_{2}$ and the linear-gas velocity was $0.045 \mathrm{~m} / \mathrm{s}$. No measurable pressure drop was found. The reactor used here was only operated under integral conditions $\left(\mathrm{O}_{2}\right.$ conversion $\left.<40 \%\right)$. The reaction rates shown are, therefore, overall rates of reaction and are not attributed to intrinsic rates of reaction. It is impossible to assign these values on a per active site basis as catalyst facetting and sintering leads to large changes in the active surface area during the reaction. Reaction rates and conversions are, therefore, normalized to the catalyst weight. The following definitions are used throughout:

-Rate of $\mathrm{O}_{2}$ consumption((Mol Reactant ${ }_{\text {in }}-\mathrm{Mol}$ Reac$\left.\operatorname{tant}_{\text {out }}\right) /($ Mol Reactant in $) \times\left(\mathrm{O}_{2}\right.$ Flow $)$

$\bullet \% \mathrm{C}_{2}$ Product selectivity $=\left(2 \mathrm{x}(\mathrm{Mol}\right.$ Product $) /\left(\mathrm{Mol} \mathrm{CH}_{4 i n}\right)-$ $\left.\left(\mathrm{Mol} \mathrm{CH}_{4 \mathrm{out}}\right)\right) \times 100 \%$

$\bullet \% \mathrm{CO}_{\mathrm{x}}$ Product selectivity $=\left((\mathrm{Mol}\right.$ Product $) /\left(\mathrm{Mol} \mathrm{CH}_{4 i n}\right)-$ $\left.\left(\mathrm{Mol} \mathrm{CH}_{4 \text { out }}\right)\right) \times 100 \%$ 
Reaction products were measured by on-line GC analysis with a Varian 3400 series gas chromatograph with thermal conductivity detector. The components were separated with a Carboxen 1000, carbon molecular seive column. All components except water could be quantitatively measured with this set-up. The reactor was allowed to equilibrate for 20 min after a change in reaction temperature prior to performing the GC analysis. TDS measurements were made in an UHV chamber with an average background pressure of $3 \times 10^{-8}$ mbar (background gas is primarily $\mathrm{H}_{2} \mathrm{O}$ ). Monitoring of desorption products was made with a Hiden (Hal2) quadrupole mass spectrometer coupled to a NEXT workstation. A sampling rate of $1 \mathrm{~s}$ was standard. A water-cooled, infrared oven was used for sample heating. The thermocouple (Type K) was placed immediately below the sample and was in direct contact with the quartz holding tube. Linear heating rates from room temperature to $1000 \mathrm{~K}$ were possible with this setup. A heating rate of $1 \mathrm{~K} / \mathrm{s}$ was used for all TDS runs. A special pretreatment procedure was used in order to minimize the amount of carbon present in the sample. This consisted of treating the sample in flowing $\mathrm{O}_{2}(17 \mathrm{ml} / \mathrm{min})$ at $973 \mathrm{~K}$, transferring to the UHV through air and subsequently performing numerous oxidation-reduction cycles. This had to be done for approximately one week before a sufficiently clean sample was obtained. It was impossible to completely remove all the carbon present in the sample.

\section{Results and Discussion}

It was mentioned in the introduction that the oxidative coupling of methane is, in many ways, an excellent test reaction for studying silver-catalyzed partial oxidation reactions at elevated temperatures. It is shown below that diffusion limitations and local temperature gradients which dominate in the methanol oxidation reaction are not present for the OCM reaction. This is a critical point as many of the previous articles regarding the methanol oxidation reaction did not take these effects into consideration ${ }^{25-28}$.

The absence of radial temperature gradients: Evidence for the absence of radial temperature gradients may be determined using the criteria developed by Dautzenberg ${ }^{25}$. This is shown as Equation 1.

Equation 1.

$\frac{L}{d_{p}}>(92.0) N_{\mathrm{Re}_{p}}^{-0.23} \ln \frac{1}{1-x} ; N_{\mathrm{Re}}=\frac{\rho D v}{\mu}$

$L$ is the necessary reactor bed length, $d_{p}$ is the catalyst particle diameter, $N_{R e}$ is the Reynold's number, $\rho$ is the gas density, $v$ is the linear flow velocity, $\mu$ is the gas viscosity, $D$ is the reactor diameter and $x$ is the integral conversion. Typical values of $N_{R e}$ obtained for both the methanol synthesis reaction and the methane coupling reaction fall in the range of $25-75^{25-28}$. Particle sizes used in this study are between 0.2 and $0.4 \mathrm{~mm}$ and the bed height is typically $1.0 \mathrm{~cm}$.
This results in a $\frac{L}{d_{p}}$ ratio of 25 or 50 . Insertion of the calculated $N_{R e}$ with a maximum methane conversion of $5 \%$ (worst case scenario) into Equation 1 results in a value of 1.74 or 2.25 for particle diameters of 0.2 or 0.4 respectively. This is significantly smaller than the necessary value of $\frac{L}{d_{p}}$ of 25 or 50 (depending on $d_{p}$ ) for typical methane coupling conditions ${ }^{18,19,20,21}$. Axial variations in temperature are, therefore, negligible for the OCM reaction. Methanol oxidation, on the other hand, often results in methanol conversions of $70 \%$. This would require an $\frac{L}{d_{p}}$ ratio of 53 or 41 for Re values of 25 or 50 . Typical $\frac{L}{d_{p}}$ ratios quoted in the literature for methanol oxidation are between 2.5 and 20 25-28. The actual value is smaller than the value calculated using Equation 1. This indicates that radial temperature gradients are likely to be present in the case of methanol oxidation. The low conversions obtained in the OCM reaction, therefore, not only enable the measurement of the reaction kinetics, but also allow for a far more accurate determination of the relevant reaction parameters.

The presence of local hot spots: It was mentioned in the introduction that another reason for deciding to study the OCM reaction instead of methanol oxidation is that the low conversions obtained for the OCM reaction result in less local heating of the catalyst bed. In principle, both the direct dehydrogenation of methanol to formaldehyde and the coupling of methane to ethane or ethylene are endothermic reactions (See Equations 2 and 3).

Equation 2.

$\mathrm{CH}_{3} \mathrm{OH} \rightarrow \mathrm{CH}_{2} \mathrm{O}+\mathrm{H}_{2} \quad \Delta H=+84 \mathrm{~kJ} / \mathrm{mol}$

Equation 3.

$2 \mathrm{CH}_{4} \rightarrow \mathrm{C}_{2} \mathrm{H}_{6}+2 \mathrm{H}_{2} \quad \Delta H=+66 \mathrm{~kJ} / \mathrm{mol}$

Equation 4.

$\mathrm{C}_{2} \mathrm{H}_{6}+\mathrm{O}_{2} \rightarrow 2 \mathrm{CO}+3 \mathrm{H}_{2} \quad \Delta H=-136 \mathrm{~kJ} / \mathrm{mol}$

Equation 5.

$\mathrm{CO}+\frac{1}{2} \mathrm{O}_{2} \rightarrow \mathrm{CO}_{2}$

$\Delta H=-68 \mathrm{~kJ} / \mathrm{mol}$

Equation 6.

$\mathrm{H}_{2}+\frac{1}{2} \mathrm{O}_{2} \rightarrow \mathrm{H}_{2} \mathrm{O}$

$\Delta H=-243 \mathrm{~kJ} / \mathrm{mol}$

Equation 7.

$\mathrm{CH}_{3} \mathrm{OH}+\frac{3}{2} \mathrm{O}_{2} \rightarrow \mathrm{CO}_{2}+2 \mathrm{H}_{2} \mathrm{O} \quad \Delta \mathrm{H}=-674 \mathrm{~kJ} / \mathrm{mol}$

The exothermicity of reaction arises from oxidation of the organic substrate (Equations 4,5 and 7) and the reaction of oxygen with the hydrogen produced from reaction (Equation 6). The degree of local heating may be estimated mathematically as follows. First, a number of simplifying assump- 
tions have been made. Heat is assumed to arise only from the heat of reaction. Convective and radiative heat transfer from the oven to the catalyst bed is neglected (worse case scenario). Secondly, the convective removal of heat is assumed to occur entirely via transport in the helium stream. This is a valid assumption as helium exhibits the highest thermal conductivity and is present in excess of all products and reactants (See experimental). The heat balance obtained appears in Equation 8.

Equation 8 .

$$
Q-F_{A 0} \sum \Theta_{i} C_{p i}\left(T-T_{i 0}\right)-F_{A 0} X\left[\Delta H_{R}\right]=0
$$

$\mathrm{Q}$ is the convective heat removal from the reactor, $\mathrm{X}$ is the reactant conversion, $\Theta$ is the stoichiometric factor for the component $\mathrm{i}$ with heat capacity $C_{p i}$, being fed to the reactor with the molar flow rate, $F_{A 0}$. T is the gas-phase temperature and $\mathrm{T}_{\mathrm{io}}$ is the surface temperature. Exact values of $C_{p i}$ depend, of course, on the exact product-reactant compositions. $C_{p}$ is also approximated using that of helium. The actual value of $C_{p}$ is likely to be smaller, so assuming the value for helium should result in a slight underestimation of the temperature rise due to the heat of reaction. The He concentration assumed here $(90 \%)$ is a typical gas-phase concentration for a number of literature references concerning formaldehyde synthesis. ${ }^{26,27,28}$

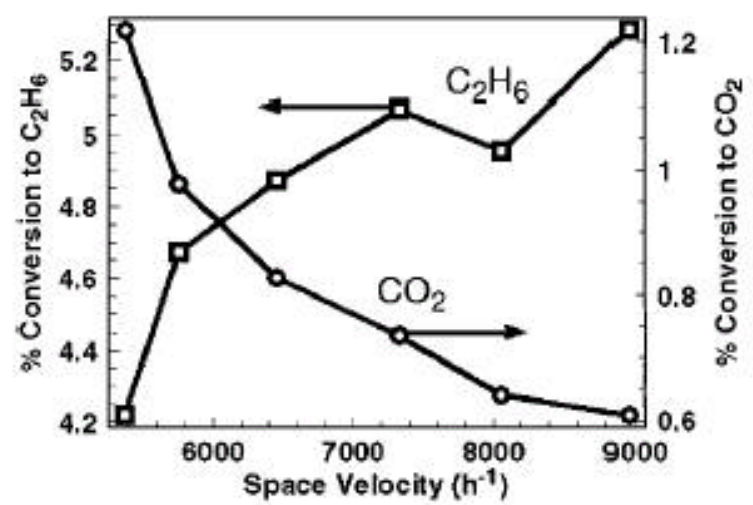

Fig. $2 \%$ Conversion to $\mathrm{C}_{2} \mathrm{H}_{6}$ and $\mathrm{CO}_{2}$ as a function of space velocity. $0.2-0.4 \mathrm{~mm}$ diameter, $8.4 \mathrm{ml} / \mathrm{min} \mathrm{O}_{2}, 50 \mathrm{ml} / \mathrm{min}$ $\mathrm{CH}_{4}, 77 \mathrm{ml} / \mathrm{min} \mathrm{He}, \mathrm{v}_{\mathrm{l}}=0.045 \mathrm{~m} / \mathrm{s}$.

Evidence for the reaction in series of methane first to $\mathrm{C}_{2}$ hydrocarbons and then subsequently to $\mathrm{CO}_{2}$ is seen in Figure 2. The reactant/product profile is shown as a function of the space velocity. The $\mathrm{CO}_{2}$ selectivity clearly increases with increasing reactor length indicating that the coupling and complete oxidation reactions take place in series and not in parallel. This is in agreement with a number of investigations of methane coupling in the literature. Ekstrom et al. ${ }^{29}$ studied methane coupling over a $\operatorname{Sm}_{2} \mathrm{O}_{3}$ catalyst and Nelson et al. ${ }^{30}$ investigated $\mathrm{Li} / \mathrm{MgO}$. These studies determined that reaction at temperatures greater than $1010 \mathrm{~K}$ results in preferential $\mathrm{CO}_{\mathrm{x}}$ formation from $\mathrm{C}_{2}$ products and not from the methane feed. These results agree well with the findings found here that the $\mathrm{CO}_{\mathrm{x}}$ products formed over silver are the result of the oxidation of $\mathrm{C}_{2}$ products over oxygencontaining silver sites. The selectivity to $\mathrm{CO}_{\mathrm{x}}$ products was not observed to change upon increasing the dead volume of the reactor. This is shown in Figure 3. Increasing the dead volume only results in an overall increase in reaction rate. This is a result of the increased volume for the gas-phase recombination of methyl radicals to $C_{2}$ products $^{31,32}$.

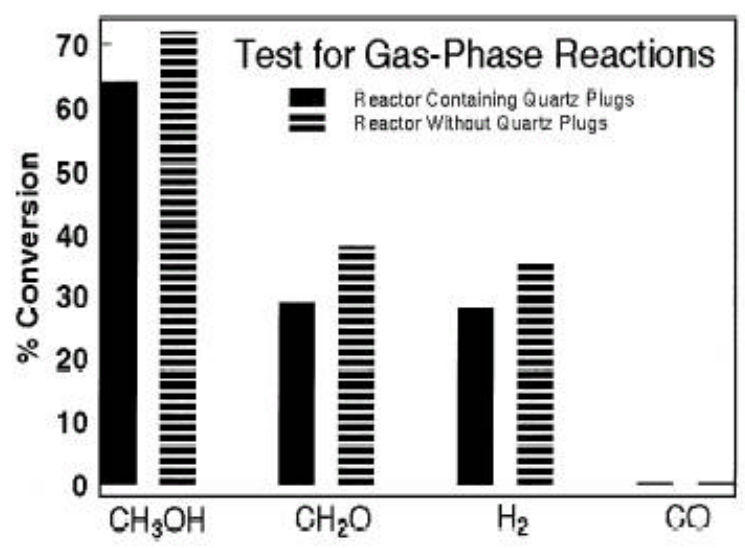

Fig. 3 The effect of increasing the dead-volume downstream of the reactor bed ( $30 \%$ increase in dead volume). $1 \mathrm{~g}$ Fresh $\mathrm{Ag}, \quad 0.2-0.4 \mathrm{~mm}$ diameter, $1 \mathrm{~g} \mathrm{SiO}_{2}, 200 \mu \mathrm{m}$ diameter, $8.4 \mathrm{ml} / \mathrm{min} \mathrm{O}_{2}, 50 \mathrm{ml} / \mathrm{min} \mathrm{CH}_{4}, 77 \mathrm{ml} / \mathrm{min} \mathrm{He}, \mathrm{S} . \mathrm{V} .=16,113$ $\mathrm{hr}^{-1}, \mathrm{v}_{\mathrm{l}}=0.045 \mathrm{~m} / \mathrm{s}$.

Inserting the appropriate steady-state stoichiometric coefficients into Equation 8 for $\Delta \mathrm{H}_{\mathrm{rxn}}$ (OCM selectivity: $80 \%$ $\mathrm{C}_{2} \mathrm{H}_{6}, 20 \% \mathrm{CO}_{2}, 30 \% \mathrm{O}_{2}$ conversion; formaldehyde synthesis selectivity: $70 \% \mathrm{CH}_{2} \mathrm{O}, 30 \% \mathrm{CO}_{2}$ ), one obtains a calculated temperature rises of $88 \mathrm{~K}$ for the OCM reaction and $944 \mathrm{~K}$ for the methanol oxidation. No conductive heat transfer from the catalyst bed to the reactor walls was considered in the calculation. This calculation shows that local heating effects are present in the case of methanol oxidation over silver. The extremely high temperature rise calculated would explain the melted appearance of the silver catalyst after methanol reaction shown in Figure 4a. Figure $4 \mathrm{~b}$ shows that the silver surface is crystalline after having been used in the OCM reaction. Silver does not appear to melt under OCM reaction conditions. The lack of local heating effects for the OCM reaction obviously eliminates the ambiguity arising from the inability to directly measure the temperature at the catalyst surface. It is worth noting that the exceptionally high temperature rise of $944 \mathrm{~K}$ calculated here has been observed experimentally by Flytzani-Stephanopoulos et al. ${ }^{33}$ using a pyrometer to study the $\mathrm{NH}_{3}, \mathrm{C}_{3} \mathrm{H}_{8}$ and $\mathrm{CO}$ oxidation reactions over Pt catalysts. These authors measured surface temperatures between 800 and $1500 \mathrm{~K}$ while the gas-phase temperature was $300 \mathrm{~K}$. This shows the magnitude of uncertainty encountered when using a thermocouple separated from the reactor by quartz, a relatively poor thermal conductor; $(15-20) \times 10^{-4} \mathrm{cal} \cdot \mathrm{cm} / \mathrm{cm}^{2} \cdot s \cdot{ }^{0} \mathrm{C}$. Locating the ther- 
mocouple directly in the catalyst bed would also likely not show the actual catalyst surface temperature but rather an average value representative the temperature of the thermocouple itself and the entire catalyst bed.

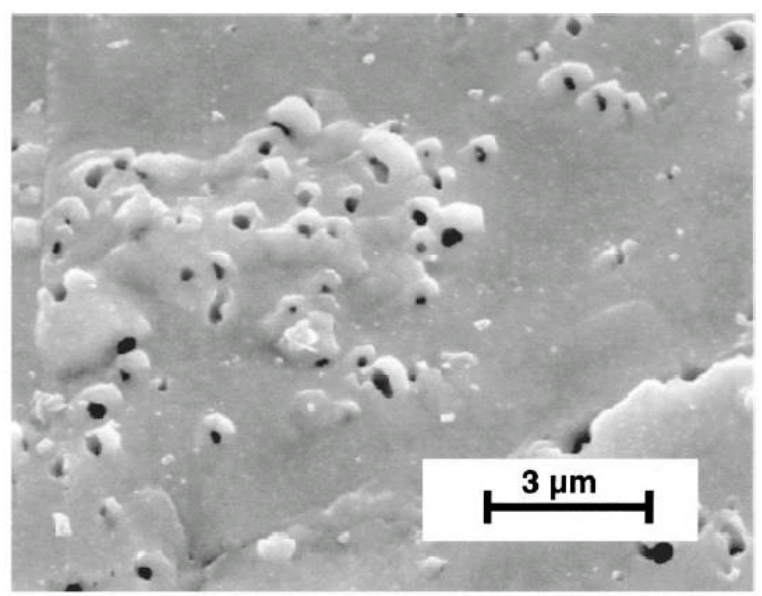

Fig. 4a SEM micrograph of a silver surface after having undergone methanol oxidation.

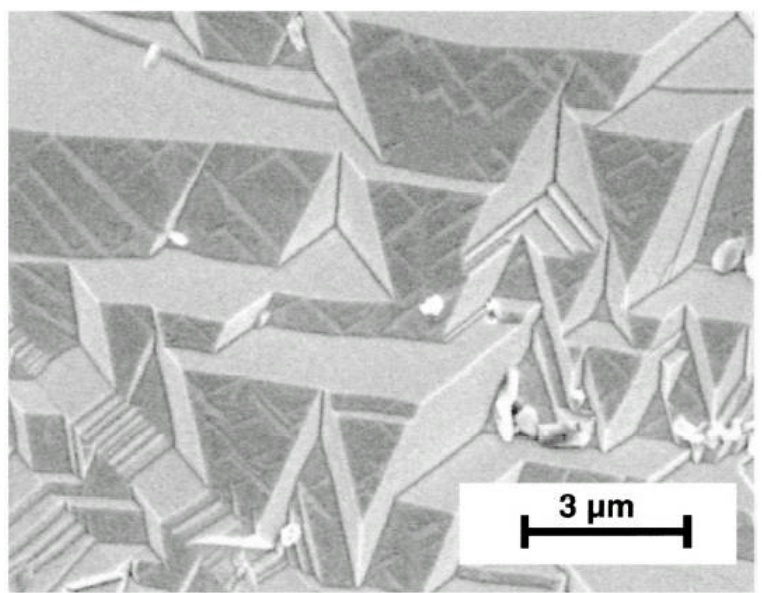

Fig. 4b SEM micrograph of a silver surface after undergoing the oxidative coupling of methane.

Earlier work attributed the formation of holes in the surface of silver to the recombination of bulk hydroxyls to water which results in a stress buildup in the bulk and ultimately in rupture ${ }^{9-11,14,15,17-23,25-27}$. The findings here do not dispute this theory, but do show that the melted appearance of the surface is likely due to a localized melting of the surface. The silver is in a very dynamic state of change during catalytic reaction. No estimations were made in these earlier works for the possible presence of local temperature gradients.

\section{$\mathrm{C}_{2} \mathrm{H}_{6}$ and $\mathrm{C}_{2} \mathrm{H}_{4}$ Formation. Reaction in series or paral-} lel?

Figure 5 shows the \% conversion of $\mathrm{CH}_{4}$ to $\mathrm{C}_{2} \mathrm{H}_{4}$ and $\mathrm{C}_{2} \mathrm{H}_{6}$ as a function of the space velocity. The nearly identical variation of conversion to both products as a function of space velocity suggests that both products are formed in parallel from $\mathrm{CH}_{4}$. Therefore, either $\mathrm{C}_{2} \mathrm{H}_{6}$ and $\mathrm{C}_{2} \mathrm{H}_{4}$ are formed in parallel or the $\mathrm{C}_{2} \mathrm{H}_{4}$ formation from $\mathrm{C}_{2} \mathrm{H}_{6}$ occurs very quickly. Reaction to $\mathrm{C}_{2} \mathrm{H}_{4}$ via the formation of $\mathrm{CH}_{2}$ : radicals directly from $\mathrm{CH}_{4}$ has been shown to be most unlikely ${ }^{34}$. The kinetics of the dehydrogenation of $\mathrm{C}_{2} \mathrm{H}_{6}$ to $\mathrm{C}_{2} \mathrm{H}_{4}$ are, therefore, likely to be too fast to result in a substantial difference in the form of the concentration profiles of $\mathrm{C}_{2} \mathrm{H}_{4}$ and $\mathrm{C}_{2} \mathrm{H}_{6}$ in the reactor bed. The latter is a reasonable assumption as the $\mathrm{C}-\mathrm{H}$ bond strength of $\mathrm{C}_{2} \mathrm{H}_{6}(422$ $\mathrm{kJ} / \mathrm{mol})$ is less than in $\mathrm{CH}_{4}(439 \mathrm{~kJ} / \mathrm{mol})$ and should lead to a preferential reaction of $\mathrm{C}_{2} \mathrm{H}_{6}$.

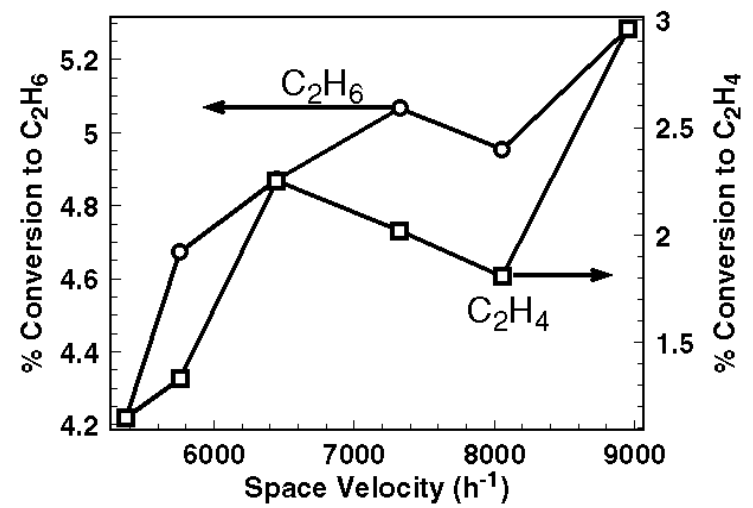

Fig. $5 \%$ Conversion to $\mathrm{C}_{2} \mathrm{H}_{6}$ and $\mathrm{C}_{2} \mathrm{H}_{4}$ as a function of space velocity. $0.2-0.4 \mathrm{~mm}$ diameter, $8.4 \mathrm{ml} / \mathrm{min} \mathrm{O}_{2}, 50$ $\mathrm{ml} / \mathrm{min} \mathrm{CH}_{4}, 77 \mathrm{ml} / \mathrm{min} \mathrm{He}, \mathrm{v}_{\mathrm{l}}=0.045 \mathrm{~m} / \mathrm{s}$.

The Arrhenius-temperature dependence of the OCM reaction: The Arrhenius temperature dependences of the reaction rate $\left[\mathrm{mol} \mathrm{O} \mathrm{O}_{2}\right.$ converted $\left./\left(\mathrm{m}^{2} \mathrm{Ag} \mathrm{min}\right)\right]$ are shown in Figure 6. Intrinsic changes of the catalyst or the presence of

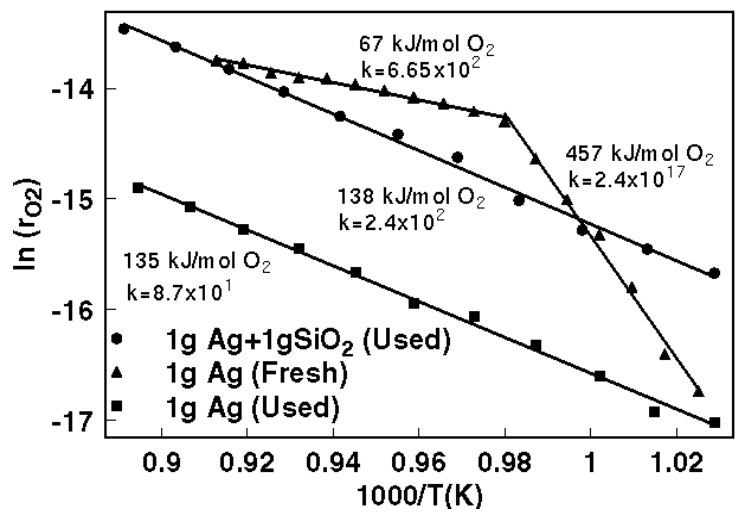

Fig. 6 Arrhenius plots for the OCM reaction over both fresh and used silver catalysts with and without $\mathrm{SiO}_{2}$ thinning.

diffusion control results in the appearance of one inflection point in the Arrhenius plot for the fresh Ag catalyst with increasing reaction temperature. This inflection point could not be detected in the Arrhenius data when the catalyst was aged at high temperatures and subsequently cooled down (data not shown). Reaction over the fresh catalyst shows an 
initially extremely high activation energy of $457 \mathrm{~kJ} / \mathrm{mol}$. This portion of the curve corresponds to the observed total oxidation of $\mathrm{CH}_{4}$ to $\mathrm{CO}_{2}$. The inflection point in the Arrhenius curve is found at $1023 \mathrm{~K}$, above which a very small activation energy of $67 \mathrm{~kJ} / \mathrm{mol}$ is measured. This indicates a change of the heterogeneously catalyzed reaction of $\mathrm{CH}_{4}$ with $\mathrm{O}_{2}$ over a catalyst which is undergoing a solid-state transformation. At low temperatures, $\mathrm{CH}_{4}$ primarily reacts with surface $\mathrm{O}_{\alpha}$ to $\mathrm{CO}_{2}$, above $1023 \mathrm{~K}$ the coupling products are increasingly formed. The preferential reaction of $\mathrm{CH}_{4}$ to $\mathrm{CO}_{2}$ over the fresh catalyst is due to the abundance of $\mathrm{O}_{\alpha}$ which forms on the large number of high-index terminating crystalline planes which are present on a fresh polycrystalline silver catalyst. The simultaneous restructuring and sintering of the catalyst during the catalytic reaction explains the exceptionally low measured apparent activation energy of $67 \mathrm{~kJ} / \mathrm{mol}$. During this process, the surface restructures forming the thermodynamically-stable (111) terminating planes. These planes have a low sticking coefficient for the formation of $\mathrm{O}_{\alpha}\left(<10^{-6}\right)$. Facetting to (111) planes results, therefore, in a decrease in the overall reaction rate due to reaction with the highly active $\mathrm{O}_{\alpha}$ species. The preferential reaction with $\mathrm{O}_{\gamma}$ which is formed via bulk diffusion to the (111) planes is the dominant reaction at elevated temperatures. $\mathrm{O}_{\gamma}$ is less reactive (lower overall rate of reaction), but reacts more selectively to $\mathrm{C}_{2}$ coupling products. No Arrhenius plots for the formaldehyde synthesis reaction under industrially relevant reaction conditions are known to this author. The presence of diffusion control in the formaldehyde synthesis reaction makes determination of the apparent activation energy impossible with this type of reactor set-up.

The irreversibility of reaction: The irreversibility of the catalyst transformation was tested by aging the catalysts with and without mixing with $\mathrm{SiO}_{2}$, cooling and repeating the identical run. The absence of inflection points for these runs shown in Figure 6 confirms the assumption that no further changes in the intrinsic catalyst activity occur during reaction. This also proves that the presence of an inflection point for reaction over the fresh catalyst was not due to the presence of boundary layer or pore diffusion control. Furthermore, the nearly identical activation energies of 135 and $138 \mathrm{~kJ} / \mathrm{mol}$ determined for these reactions indicate that the same reaction mechanisms are active for both the pure $\mathrm{Ag}$ as well as that mixed with $\mathrm{SiO}_{2}$. The pre-exponential factor for the sample containing $\mathrm{SiO}_{2}\left(2.4 \times 10^{2} \mathrm{~mol} \mathrm{O}_{2} / \mathrm{g} \mathrm{s}^{-1}\right)$ is, however, nearly three times larger than that of the sample without $\mathrm{SiO}_{2}\left(8.7 \times 10^{1} \mathrm{~s}^{-1} \mathrm{~mol} \mathrm{O} / \mathrm{g} \mathrm{s}^{-1}\right)$. An increased preexponential factor indicates that more active sites are present on the sample which was thinned with $\mathrm{SiO}_{2}$. This results from the fact that the catalyst thinned with $\mathrm{SiO}_{2}$ is less sintered than the pure $\mathrm{Ag}$ sample.

The correlation of reaction rate with bulk-oxygen diffusion: One of the key points of this work was to determine if a correlation exists between the oxygen diffusion kinetics in electrolytic silver and the reaction kinetics of the OCM reaction. The proposed model was shown schematically in Fig- ure 1. It is suggested that molecular oxygen is activated at the silver surface where it forms atomically adsorbed oxygen $\left(\mathrm{O}_{\alpha}\right)$. On the one hand, $\mathrm{O}_{\alpha}$ may react with $\mathrm{CH}_{4}$ or any reactant which is reductive in nature $\left(\mathrm{H}_{2}, \mathrm{C}_{2}\right.$ Products, etc) to form $\mathrm{H}_{2} \mathrm{O}$ and $\mathrm{CO}_{\mathrm{x}}$. $\mathrm{O}_{\alpha}$ may also diffuse into the silver bulk forming $\mathrm{O}_{\beta}$ via interstitial diffusion which transforms to $\mathrm{O}_{\gamma}$ via interstitialcy diffusion. The high sticking coefficient of the (110) surface suggests that this occurs $\left[\theta_{(110)} \approx 10^{-3} ; \theta_{(111)} \leq 10^{-6}\right]$

preferentially via adsorption on and diffusion through the (110) terminating side of the crystal facet via octahedral hole jumping along the [110] direction ${ }^{32}$. At elevated temperatures $(\mathrm{T}>900 \mathrm{~K})^{44}$, the Ag surface and bulk reconstructs to form the thermodynamically must (111) surfaces and the interstitialcy diffusion of oxygen through the silver lattice is activated by which oxygen substitutes for silver. Diffusion through (111) terminating facets then becomes possible. Figure 7 shows an Arrhenius evaluation of the TDS data for
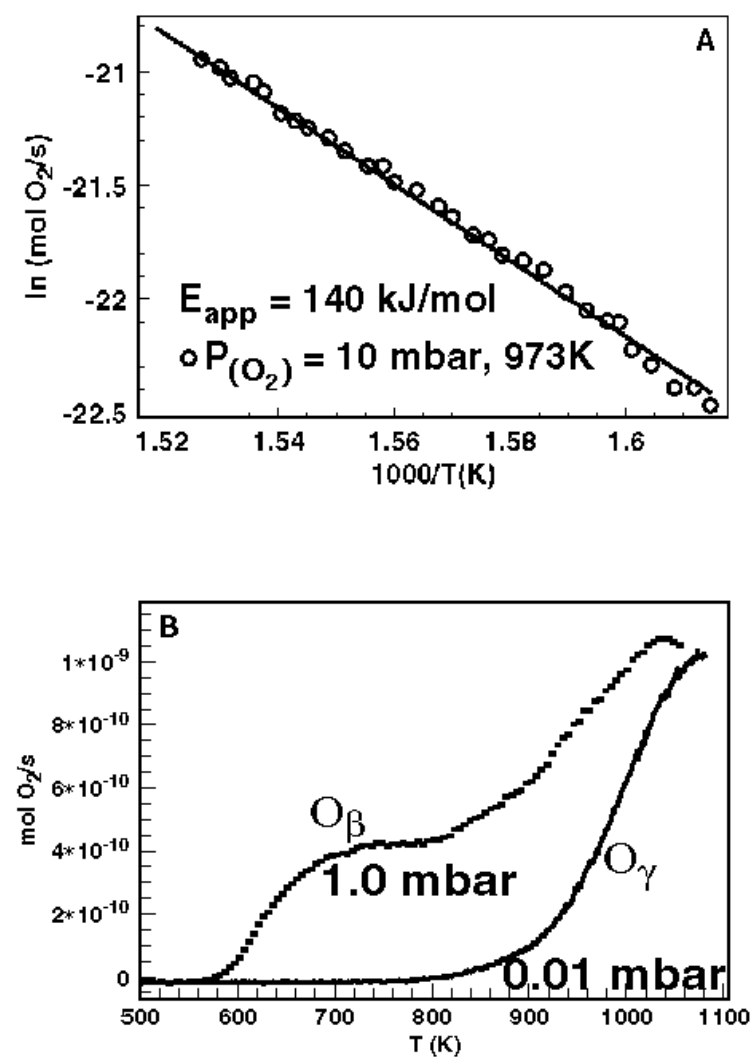

Fig. 7 A. Arrhenius plot of a temperature-programmed desorption spectra using the front line method. $1 \mathrm{~g} \mathrm{Ag}$, $100 \mathrm{mbar} \mathrm{O}_{2}, 973 \mathrm{~K}, 5 \mathrm{~min}$ dose, $1 \mathrm{~K} / \mathrm{s}$ heating rate. $\mathrm{B}$. TDS Experiments.

a 0.01 mbar dose of $\mathrm{O}_{2}$ over silver at $1073 \mathrm{~K}$ (solid line) as compared to a TDS trace after dosing $1 \mathrm{mbar}_{2}$. The form of the TDS curve taken under such conditions is governed by the bulk diffusion mechanism of oxygen in $\mathrm{Ag}^{35}$. Bulk diffusion is the rate limiting step in such an experiment and not surface recombination and/or desorption as in usual 
surface science TDS. This is a critical point to understand. The kinetics of a bulk diffusion process are many orders of magnitude lower than surface processes. During the TDS measurement, the sample was quenched rapidly from 1073 $\mathrm{K}$ to room temperature, essentially freezing the bulk oxygen into the silver structure. Surface bound oxygen is pumped off in this process and does not appear in the TDS spectra. It is assumed that the concentration-dependent activation energy does not vary in the temperature region used for the determination of the activation energy of diffusion (beginning of thermal desorption). This assumption is corroborated by the fact that a linear Arrhenius relationship is obtained for the TDS trace after dosing $0.01 \mathrm{mbar}_{2}$. An activation energy for diffusion of $140 \mathrm{~kJ} / \mathrm{mol}$ was determined from the slope of the line shown. The correlation between the activation energy of reaction shown in Figure $6(138 \mathrm{~kJ} / \mathrm{mol})$ and that of oxygen diffusion in silver $(140 \mathrm{~kJ} / \mathrm{mol})$ in Figure 7 provides strong evidence for the supposition that the formation and diffusion of a bulk-dissolved oxygen species is the rate-limiting step of reaction.

Time-dependent variations in catalyst activity: Equivalent amounts (1 $\mathrm{g} \mathrm{Ag}: 1 \mathrm{~g} \mathrm{SiO}_{2}$ ) of silver and $\mathrm{SiO}_{2}$ were mixed and placed in the reactor. The rate of $\mathrm{O}_{2}$ reaction obtained at different reaction temperatures with this catalyst mixture is shown in Figure 8. Reaction over the catalyst mixed with

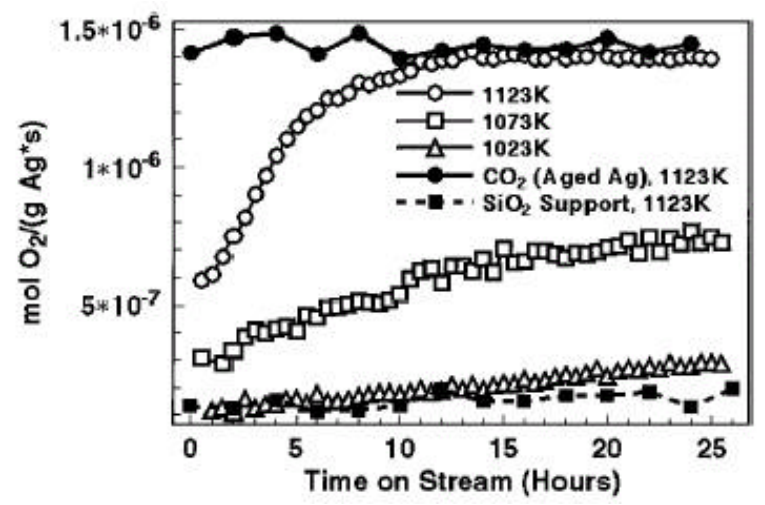

Fig. 8 Rate of $\mathrm{O}_{2}$ consumption as a function of time and temperature for reaction over a fresh silver catalyst mixed with $\mathrm{SiO}_{2}$. $1 \mathrm{~g}$ Fresh $\mathrm{Ag}, 0.2-0.4 \mathrm{~mm}$ diameter, $1 \mathrm{~g} \mathrm{SiO}_{2}$, $200 \mu \mathrm{m}$ diameter, $8.4 \mathrm{ml} / \mathrm{min} \mathrm{O}_{2}, 50 \mathrm{ml} / \mathrm{min} \mathrm{CH}_{4}, 77 \mathrm{ml} / \mathrm{min}$ He, S.V.= 16,113 hr ${ }^{-1}, \mathrm{v}_{\mathrm{l}}=0.045 \mathrm{~m} / \mathrm{s}$.

$\mathrm{SiO}_{2}$ shows a gradual activation with increasing time on stream. The activation shows an initial rapid increase in the first 7 hours followed by a more gradual increase for times longer than 20 hours. The presence of more than one activation profile suggests that more than one type of solid-state transformation is responsible for the observed activation. The time necessary for the $\mathrm{O}_{2}$ reaction rate to reach steadystate varies as a function of the reaction temperature. This arises from the temperature dependence of the silver interdiffusion coefficient which determines the rate at which the catalyst reconstruction takes place. Quantitative evidence for this is provided in the next section. The solid-state reaction resulting in increased activity occurs on the time scale of hours with steady-state being reached after 15 hours on stream for the run made at $1123 \mathrm{~K}$ (Figure 8). An increase in the formation of the catalytically active $\mathrm{O}_{\gamma}$ with time on stream as a result of surface facetting ${ }^{17-22,28}$ would explain the gradual increase in catalytic activity. The reversibility of this catalyst activation was tested by cooling the sample under the reacting gas and repeating a run at $1123 \mathrm{~K}$. The results are shown as filled circles in Figure 8. The aged catalyst is active over the course of the entire run, indicating the irreversibility of the solid-state transformation of the catalyst which occurred during the previous reaction.

Changes in selectivity: The variation of the selectivity with time on stream is seen in Figure 9. The sample initially shows an elevated selectivity to $\mathrm{CO}$. This decreases rapidly within the first 10 hours on stream to $15 \%$ and the selectivity to coupling products increases to $65 \%$.

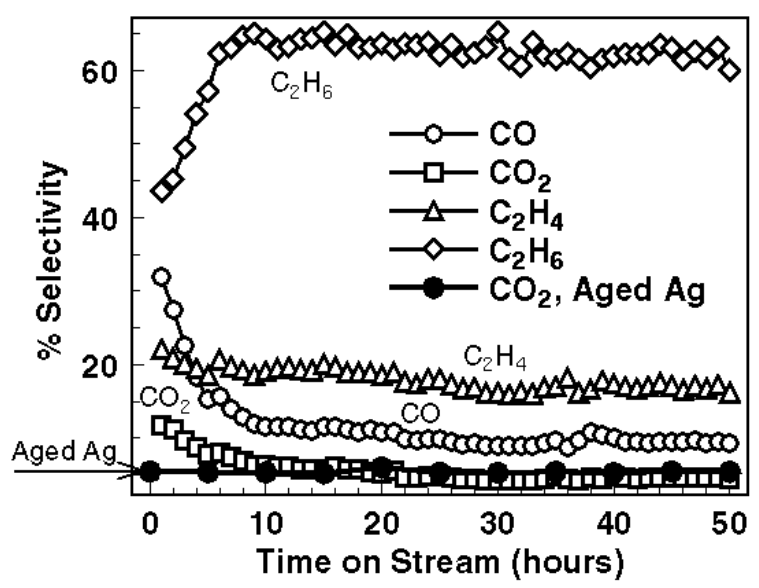

Fig. 9 Selectivity for reaction over a fresh silver catalyst mixed with $\mathrm{SiO}_{2}$. $1 \mathrm{~g}$ Fresh $\mathrm{Ag}, 0.2-0.4 \mathrm{~mm}$ diameter, $1 \mathrm{~g}$ $\mathrm{SiO}_{2}, 200 \mu \mathrm{m}$ diameter, $8.4 \mathrm{ml} / \mathrm{min} \mathrm{O}_{2}, 50 \mathrm{ml} / \mathrm{min} \mathrm{CH}_{4}, 77$ $\mathrm{ml} / \mathrm{min} \mathrm{He}, \mathrm{S} . \mathrm{V} .=16,113 \mathrm{hr}^{-1}, \mathrm{v}_{\mathrm{l}}=0.045 \mathrm{~m} / \mathrm{s}$.

The reversibility of the solid-state transformation responsible for this variation in selectivity was tested by subsequent cooling the reactor to $1023 \mathrm{~K}$ under the reactant stream and then repeating the identical run. The filled circles in Figure 9 shows that the initially high CO selectivity does not appear for reaction over an aged sample. The used catalyst appears to have undergone a transformation which has changed it from a catalyst which favors complete oxidation to one exhibiting an excellent selectivity to $\mathrm{C}_{2}$ products. No carbon deposition was observed by SEM or EDX analysis after reaction. Catalyst restructuring therefore transforms silver from a relatively inactive catalyst favoring total oxidation into a more active catalyst favoring dehydrogenation.

The variation of activation energy with time on stream: The variation of the apparent activation energy of reaction as a function of time on stream may be calculated by plotting points at identical times on stream for the three curves shown in Figure 8 in the Arrhenius form. The variation in 
the calculated apparent activation energy as a function of time on stream is shown in Figure 10. The initial apparent

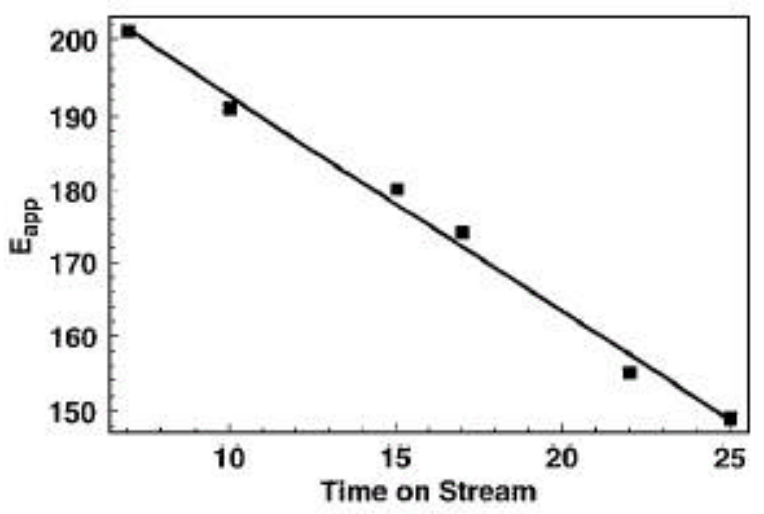

Fig. 10 Variation of the calculated apparent activation energy as a function of time on stream.

activation energy of reaction $200 \mathrm{~kJ} / \mathrm{mol}$ decreases linearly until a steady-state value of approximately $140 \mathrm{~kJ} / \mathrm{mol}$ is reached. This decrease in $\mathrm{E}_{\text {app }}$ with time on stream may be explained in two ways. The facetting of the surface and bulk texturing may lead to a decreased barrier to bulk diffusion resulting in a decrease in the observed apparent activation energy of reaction. It has been shown that the treatment of silver in an oxygen-containing atmosphere results in surface facetting and bulk texturing which favor enhanced diffusion of oxygen through the silver bulk ${ }^{35}$. It may also be that the observed apparent activation energy decreases as the role of gas-phase, homogeneous reactions decreases and the heterogeneously-catalyzed surface reaction increases with increased facetting. In either case, it is clear that the decrease in apparent activation energy as a function of time on stream indicates that the dominant reaction mechanism varies as a function of time on stream.

Evidence for surface-diffusion controlled facet growth: Investigation of the time-dependence of the activation profiles shown in Figure 8 yields information about the mechanism of mass transfer resulting in surface facetting. The increase in activity for the run at $1073 \mathrm{~K}$ follows a power law of the following form.

Equation 16.

$$
\frac{d\left[\mathrm{O}_{2}\right]}{d t}=K \times t^{0.24}
$$

The 0.24 power law dependence agrees excellently with the value of 0.25 for the silver facetting kinetics predicted by Mullins et al. ${ }^{36}$ for surface-diffusion controlled facetting. This is, therefore, a quantitative tie between facet growth kinetics and catalyst activation kinetics for the OCM reaction in this temperature region. This finding is also in agreement with the previously made hypothesis that the dominant mechanism for facetting under these conditions was surface diffusion of silver and not sublimation and recondensation. A deviation from the facet-growth behavior predicted by Mullins ${ }^{29}$ was observed for reaction at $1123 \mathrm{~K}$ (See Figure 8). This curve could only be fitted using a natural exponential function, suggesting that surface-diffusion limited facetting is no longer likely to be the dominant process. Mullins predicted a power-law relationship with an order of $1 / 3$ for facet growth dominated by sublimation and recondensation. The observed experimental time dependence shown here does not fit either of the predicted schemes (surface diffusion or sublimation). No weight loss was observed during reaction (after 1 week on line) indicating that sublimation is negligible. It is likely, therefore, that the formation of a sub-oxide is responsible for this deviation from simple surface diffusion. Silver oxides are known to have lower melting points than pure silver $\left(T_{m, A g}=961.93^{\circ} \mathrm{C}, T_{m, A g_{2} O}=230^{\circ} \mathrm{C}, T_{m, A g O}>100^{\circ} \mathrm{C}\right)^{37}$. The surface diffusion constants of many metal oxides are also higher than the corresponding pure metals ${ }^{38,39}$. Although the high reaction temperatures used here safely exclude the existence of a stoichiometric oxide, the constant pressure of gas-phase oxygen may result in the formation of sub-oxide surface layers. This implies that the coefficient of diffusion for surface diffusion is a function of the gas-phase composition (more oxygen, increased diffusion constant). This is supported by the fact that the surface reconstruction shows a strong dependence on the gas-phase composition. ${ }^{14,15,18,22,25-}$ 28,36,39 The formation of such a sub-oxide would explain the deviation from the predicted facetting kinetics. In addition, the silver inter-diffusion constant exhibits different temperature dependencies depending on whether or not diffusion occurs by an interstitial or an interstitialcy mechanism. ${ }^{40}$ The latter mechanism dominates at elevated temperatures ( $\mathrm{T}>923 \mathrm{~K})$. The fact that the transport kinetics for both silver diffusion mechanisms exhibit different temperature dependencies implies that a deviation from the kinetics predicted by Muller (based on a single activation energy) should be observed at more elevated temperatures. It is likely that both the influence of the formation of a sub-oxide as well as the shift from an interstitital to an interstitialcy diffusion mechanism results in the observed deviation from simple power-law activation kinetics at elevated temperatures.

\section{The Model}

The proposed reaction mechanism is shown in Figure 1. Reaction of methane with the surface-adsorbed $\mathrm{O}_{\alpha}$ species results in oxi-dehydrogenation and/or total oxidation. The initially rough, polycrystalline, silver surface exhibits a high sticking coefficient for $\mathrm{O}_{\alpha}$. This results, initially, in the observed preferential complete oxidation (See Figure 9). Surface adsorbed oxygen may diffuse into the silver lattice to form bulk dissolved oxygen. Bulk dissolved oxygen is differentiated by its diffusion mechanism. $\mathrm{O}_{\beta}$ diffuses to the $\mathrm{Ag}$ surface via an interstitial diffusion mechanism, or $\mathrm{O}_{\gamma}$ via an interstitialcy diffusion mechanism. Subsurface oxygen, $\mathrm{O}_{\gamma}$, formed via the intersticialy diffusion, at (111) Ag surfaces is suggested to react with methane to give the dehydrogenation of methane to a methyl radical. $\mathrm{O}_{\gamma}$ is only formed when the silver surface becomes facetted ${ }^{14,15,18,22,28,36,39}$. The increase in activity and selectivity to $\mathrm{C}_{2}$ coupling products 
with time on stream provides strong evidence that the facetting of silver and subsequent $\mathrm{O}_{\gamma}$ formation are responsible for significantly improved catalytic behavior (less complete oxidation). Hydrogen abstraction has been proposed by a number of authors to be the reaction-limiting step of reaction for OCM over a variety of catalysts. ${ }^{41,42,43}$ The gas-phase recombination of radicals occurs quickly with respect to the dehydrogenation step. ${ }^{44}$ The suggestion that the formation of $\mathrm{O}_{\gamma}$ is necessary for reaction implies that the reaction of methane is limited by the rate of bulk oxygen diffusion to the (111) surface via interstitialcy diffusion and not by the hydrogen abstraction step.

It is critical to note that silver is a permeable metal for a variety of gases

$$
\left(D_{H_{2}, 973 \mathrm{~K}}=2.82 \times 10^{-3} \mathrm{~cm}^{2} / \mathrm{s} ; D_{O_{2}, 973 \mathrm{~K}}=8.19 \times 10^{-2} \mathrm{~cm}^{2} / \mathrm{s}\right)^{45} \text {, }
$$

46. There exists, therefore, an equilibrium concentration of products and reactants in the gas-phase, on the surface and in the silver bulk (both lattice and interstitial). The concentrations of these various species in the different phases is thermodynamically governed by gradients in the chemical potential at the phase boundaries, but is often kinetically limited by the relatively slow kinetics of solid-state diffusion processes. The reactivity of active oxygen species should, therefore, mimic the kinetics of the transport process relevant to its formation. Stoichiometric reaction with surfacebound species should therefore react quickly as the formation of surface oxygen typically occurs on the time scale of pico or femto seconds. Stoichiometric reaction with bulk species should, however, take place much slower as the bulk diffusion processes necessary to the formation of these species occur on a much slower time scale of seconds.

$\mathrm{O}_{\alpha}$ is believed to participate in the oxi-dehydrogenation of methanol to formaldehyde and water and the complete oxidation of methanol and methane to complete oxidation products (See Equations 17-19).

Equation 17: Oxi-dehydrogenation:

$$
\mathrm{CH}_{3} \mathrm{OH}+\mathrm{O}_{\alpha} \stackrel{\Delta \mathrm{T}}{\longrightarrow} \mathrm{CH}_{2} \mathrm{O}+\mathrm{H}_{2} \mathrm{O}
$$

Equation 18: $\quad \mathrm{CH}_{3} \mathrm{OH}$ Combustion:

$$
\mathrm{CH}_{3} \mathrm{OH}+3 \mathrm{O}_{\alpha} \stackrel{\Delta \mathrm{T}}{\longrightarrow} \mathrm{CO}_{2}+2 \mathrm{H}_{2} \mathrm{O}
$$

Equation 19: $\quad \mathrm{CH}_{4}$ Combustion:

$$
\mathrm{CH}_{4}+4 \mathrm{O}_{\alpha} \stackrel{\Delta \mathrm{T}}{\longrightarrow} \mathrm{CO}_{2}+2 \mathrm{H}_{2} \mathrm{O}
$$

In this case, silver acts as a catalyst for the stoichiometric reaction between oxygen and methanol.

$\mathrm{O}_{\gamma}$ is a very different case in the sense that the silver-oxygen species formed acts as the catalyst for the direct dehydrogenation of organic molecules. This is shown in Equations 20 and 21 .

Equation 20: $\quad \mathrm{CH}_{3} \mathrm{OH}$ Dehydrogenation: $\mathrm{CH}_{3} \mathrm{OH} \stackrel{\mathrm{O}_{\gamma}, \Delta \mathrm{T}}{\longrightarrow} \mathrm{CH}_{2} \mathrm{O}+\mathrm{H}_{2}$
Equation 21: $\quad \mathrm{CH}_{4}$ Dehydrogenation:

$$
2 \mathrm{CH}_{4} \stackrel{\mathrm{O}_{\gamma}, \Delta \mathrm{T}}{\longrightarrow} 2 \mathrm{CH}_{3}^{+}+\mathrm{H}_{2}
$$

There is, therefore, a fundamental difference between the active catalyst for oxi-dehydrogenation or pure dehydrogenation. The silver metal functions as the catalyst in the former. $\mathrm{O}_{\gamma}$ functions as the catalyst in the latter. $\mathrm{O}_{\gamma}$ is likely consumed when it migrates from the lattice to the surface forming $\mathrm{O}_{\alpha}$ or via reaction with highly reactive reaction intermediates like atomic hydrogen or formate species. The participation of bulk oxygen in reaction has been proposed by a number of authors using a variety of different catalysts ${ }^{47,48,49}$. These studies typically proposed a Mars van Krevelen-type mechanism where the lattice oxygen of a stoichiometric oxide participates in reaction. ${ }^{50}$ No stoichiometric silver oxide is present under typical OCM reaction conditions $(\mathrm{T}>873 \mathrm{~K})$. The most stable form of silver oxide, $\mathrm{Ag}_{2} \mathrm{O}$, decomposes quickly above $673 \mathrm{~K}^{37}$. The silver catalyst acts essentially as an electron-rich substrate which may activate various types of oxygen species which each play a different role in reaction. The correlation between oxygen diffusion kinetics and the observed OCM reaction kinetics implies that the rate limiting step is not the dehydrogenation of methane to a methyl radical, but rather the formation of $\mathrm{O}_{\gamma}$ via bulk diffusion.

\section{Conclusions}

It is shown that catalyst restructuring and the formation of subsurface oxygen is necessary for the transformation of electrolytic silver from a catalyst exhibiting poor activity and selectivity to dehydrogenation products to one which is more active and selectively catalyzes the formation of direct dehydrogenation products. A number of authors have shown that the incorporation of subsurface oxygen plays a critical role in the ethylene epoxidation by modifying the silver surface electronically ${ }^{4,6,7}$. They propose that this electronically-modified silver surface is then active for olefin adsorption (particularly for ethylene). The major deviation of the model proposed in this work from the ethylene epoxide model is that subsurface oxygen is believed to play a dynamic role in the OCM reaction where it is continuously created by bulk dissolution from the gas phase and destroyed via surface segregation and reaction. The relatively low reaction temperatures for ethylene epoxidation (473-573 K) implies that the mobility of oxygen under typical ethylene epoxidation conditions is many orders of magnitude lower than under formaldehyde synthesis or OCM reaction conditions. The diffusion coefficient for oxygen diffusion in polycrystalline silver is known to exhibit an Arrhenius temperature dependence:

$$
D_{A g, P o l y}=2.96 \times 10^{-3} \exp \left(\frac{-11050}{R T}\right) \mathrm{cm}^{2} / \mathrm{s}^{45} \text {. }
$$

The high reaction temperatures used $(\mathrm{T}>923 \mathrm{~K})$ for the OCM and methanol oxidation reaction excludes the participation of stoichiometric silver oxide in reaction. In addition, no oxygen is incorporated into the organic reactant for the 
cases of methane coupling and formaldehyde synthesis. The desired reaction is a direct dehydrogenation reaction. One active oxygen species $\left(\mathrm{O}_{\gamma}\right)$ may, therefore, catalyze the formation of many product molecules (high turnover frequency) in the case of the OCM or formaldehyde synthesis reaction. $\mathrm{O}_{\gamma}$ functions, therefore, as a Lewis base center which is active for the dehydrogenation of organic molecules. The dependence of the oxygen adsorption and diffusion mechanism and rate of diffusion on the crystallographic orientation of the silver crystallites explains the strong structure sensitivity of the OCM reaction over silver. Changes in the surface and bulk morphology are intrinsically related and play key roles in the overall reaction mechanism. Catalyst activation kinetics correlate well with the predicted facet growth kinetics for facet growth by surface-diffusion ${ }^{37}$. In addition, a quantitative correlation exists between the activation energy of reaction $(138 \mathrm{~kJ} / \mathrm{mol})$ and the activation energy of oxygen diffusion in silver $(140 \mathrm{~kJ} / \mathrm{mol})$. The reaction rate is therefore limited by the formation of $\mathrm{O}_{\gamma}$ via bulk diffusion. This provides a strong argument in favor of the supposition that the formation of active oxygen $\left(\mathrm{O}_{\gamma}\right)$ via the continuous surface segregation of bulk-dissolved oxygen $\left(\mathrm{O}_{\beta}\right)$ is a necessary prerequisite to the formation of a silver catalyst which is active for direct dehydrogenation reactions.

\section{References}

1. Ullman, "Ullman's Encyclopedia of Industrial Chemistry“, 5th edition A11, 619-651 (1988).

2. Sperber H., Chemie-Ing.-Technology 41(17), 962 (1969).

3. Reuss G., Disteldorf W., Grundler O.and Hilt A., "Formaldehyde“, Verlag Chemie, Weinheim A11, 619 (1988).

4. van Santen R., and. DeGroot C., J. Catal. 98, 530 (1986).

5. Voge H., and Adams C., Adv. Catal. 17, 151 (1967).

6. Bukhtiyarov V., Boronin A., and. Savchenko V, Surf. Sci. Lett. 232, L205 (1990).

7. Boronin A., Bukhtiyarov V., Vishnevskii A., Boreskov G., and Savchenko V., Surf. Sci. 201, 195 (1988).

8. Grant R., and Lambert R., J. Catal. 92, 364 (1985).

9. Herein D., Nagy A., Schubert H., Weinberg G., Kitzelman E., and Schlögl R., Z. Phys. Chem Bd. 197, 67 (1996).

10. Lefferts L., van Ommen J., and Ross J., Appl. Cat. 23, 385 (1986).

11. Schubert H., Tegtmeyer U., Herein D., Bao X., Muhler M., and Schlögl R., Catal. Lett. 33, 305 (1995).

12. Prince K., Paolucci G., and Bradshaw A., Surf. Sci. 175, 101 (1986).

13. Frank E., and Hamers R., J. Catal. 172, 406 (1997).

14. Uwins P., Millar G., and Nelson M., Microscopy Research and Technique 36, 382 (1997).

15. Millar G., Nelson M., and. Uwins P., Catal. Lett. 43, 97 (1997).

16. Rao C., Aiyer H.,. Arunarkavalli T., and Kularni G., Catal. Lett. 23, 37 (1994).

17. Bao X., Muhler M., Schedel-Niedrig Th., and Schlögl R., Phys. Rev.B 54, 2249 (1996).

18. Herein D., Werner H., Schedel-Niedrig T., Neisius T., Nagy A., Bernd S., and Schlögl R., Proc. 3rd World Congress on Oxidation Catalysis, Eds. Oyama S.T et al., Sept 21-26 (1997).

19. Bao X., and Deng J., J. Catal. 99, 391 (1986).

20. Bao X., Lempfuhl G., Weinberg G., Schlögl R., and Ertl G., J. Chem. Soc. Faraday Trans. 88(6) , 865 (1992).

21. Bao X., Pettinger B., Ertl G., and Schlögl R., Ber. Bunsenges. Phys. Chem. 97, 97 (1993).

22. Rehren C., Muhler M., . Bao X.,. Schlögl R., and Ertl G., Z. Phys. Chem. 174, 11 (1991).

23. D. Herein, A. Nagy, to be published.

24. Bao X., Muhler M., Schlögl R., and Ertl G., Catal Lett. 32, 185 (1995).

25. F. Dautzenberg, "Ten Guideline for Catalyst Testing“, American Chemical Society 105 (1989) ISBN 0097-6156/89.

26. Leffers L., van Ommen J., and Ross J., Appl. Cat. 23, 385 (1986).

27. Lefferts L., van Ommen J., and Rosss J., Appl. Cat. 34, 329 (1987).

28. Nagy A., Mestl G., Rühle T., Weinberg, G., and Schlögl R.79, 548 (1998).

29. Ekstron A., Lapszewicz, and Campbell I., Appl. Catal. 56, L29 (1989).

30. Nelson P., and Cant N., J. Phys. Chem. 94, 3756 (1990).

31. Nelson P., Lukey A., and Cant N., J. Phys. Chem. 92, 6176 (1988).

32. Mims C., Hall R., Rose K., and Martin G., Catal. Lett. 2, 361 (1989).

33. Flytzani-Stephanopoulos M., Wong S., and Schmidt L., J. Catal. 49, 51 (1977).

34. Hutchings G., Scurrell M. in Methane Conversion by Oxidative Processes, (Ed: E.E. Wolf), van Nostrand Reinhold, N.Y., 201 (1992).

35. Nagy A., Mestl G., Herein D., G. Weinberg, E. Kitzelmann, and R. Schlögl, J. Catal., 182, 417 -429 (1999).

36. Mullins, W., Phil. Mag., Ser. 8, 6, 1313 (1961).

37. "CRC Handbook of Chemistry and Physics", CRC Press, Inc. ISBN -0-8493-0463-6, 63, B-144-145 (1984)

38. Wei Ta-Chin, and Phillips J., Adv. In Catal. 41, 359 (1995).

39. Somorjai G.A., in "Introduction to Surface Chemistry and Catalysis", John Wiley \& Sons, Inc., ISBN 0-471-03192-5 (1994).

40. Hoffman R., and Turnbull D. J. Appl. Phys. 22, 634 (1951).

41. Nelson P., Lukey C., and Cant N., J. Phys. Chem. 92, 6176 (1988).

42. Mims C., Hall R., Rose D., and Martin G., Catal. Lett. 2, 361 (1989).

43. Zhang H., Wang J., Driscoll D., and Lunsford J., J. Catal. 112, 366 (1988).

44. Campbell K., Morales E., and Lunsford J., J. Am. Chem. Soc. 109, 7900 (1987).

45. Outlaw R., Wu D., Davidson M., and Hoflund G., J. Vac. Sci. Technol. A 10(4), 1497 (1992).

46. Eichenauer W., and Pebeler A., Z. Metallkade. 48, 373 (1957).

47. Wang J., and Lunsford J., J. Phys. Chem. 90, 5883 (1986).

48. Peil K., Goodwin J., and Marcelin G. in Natural Gas Conversion, Studies in Surface Science and Catalysis (Eds: Holmen A., Jens K., and Kolbee S.), Elsevier, Amsterdam 61, 73-79 (1991). 
49. Zhang H., Wang J., Driscoll D., and Lunsford J., J. Catal. 112, 366 (1988).

50. Mars P., and van Krevelen D.W., Chem.Eng.Sci.Special Suppl. 3, 41 (1954). 